\title{
O ensino de Ciências Naturais na educação básica por meio de atividades lúdicas:
}

\section{Uma revisão da literatura}

\author{
Teaching of Natural Sciences in basic education through recreational activities: A literature review \\ La enseñanza de las Ciencias Naturales en la educación básica a través de actividades lúdicas: Una \\ revisión de la literatura
}

Recebido: 04/04/2021 | Revisado: 06/05/2021 | Aceito: 10/05/2021 | Publicado: 26/05/2021

\author{
Silvio Gentil Jacinto Junior \\ ORCID: https://orcid.org/0000-0002-4183-9932 \\ Universidade Estadual do Ceará, Brasil \\ E-mail: silvio.gentil@aluno.uece.br \\ Eliseu Marlônio Pereira de Lucena \\ ORCID: https://orcid.org/0000-0002-8190-1702 \\ Universidade Estadual do Ceará, Brasil \\ E-mail: eliseu.lucena@uece.br \\ Daniela Ribeiro Alves \\ ORCID: https://orcid.org/0000-0002-0746-2211 \\ Universidade Estadual do Ceará, Brasil \\ E-mail: alves.danielaribeiro@gmail.com \\ Selene Maia de Morais \\ ORCID: https://orcid.org/0000-0002-4000-7616 \\ Universidade Estadual do Ceará, Brasil \\ E-mail: selenemaiademorais@gmail.com
}

\begin{abstract}
Resumo
O objetivo desse trabalho é discorrer sobre as principais estratégias de ensino que vêm sendo utilizadas atualmente para promover uma melhora no rendimento de aprendizagem das ciências naturais (química, física e biologia), em alunos da educação básica: ensino fundamental e médio, em substituição a metodologia tradicional de ensino. Dessa forma, realizou-se uma pesquisa bibliográfica tratando das principais técnicas de ensino envolvendo as atividades lúdicas. Essas têm promovido uma melhora no aprendizado dos discentes, desenvolvendo a motivação para estudar, a inovação, a sociabilidade e permitindo que o aluno consiga internalizar as inter-relações entre essas disciplinas. Realizou-se ainda uma pesquisa bibliográfica considerando as contribuições de vários autores nas bases: Base Nacional Comum Curricular, Google Acadêmico, SciELO, Youtube, dentre outras, buscando a partir da argumentação destas evidenciar os benefícios dessas estratégias no processo de ensino-aprendizagem dos discentes. Os resultados demonstram que a utilização de músicas, jogos e peças teatrais promovem uma melhoria na aprendizagem discente e estimulam habilidades cognitivas que favorecem a sociabilidade, a motivação e despertam o interesse do aluno em relação ao conteúdo abordado em sala de aula. A partir dessa revisão, concluiu-se que é bastante efetiva a utilização da ludicidade em sala de aula no desenvolvimento da aprendizagem.
\end{abstract}

Palavras-chave: Ciências naturais; Atividades lúdicas; Educação básica.

\begin{abstract}
The objective of this work is to discuss the main teaching strategies that are currently being used to promote an improvement in the learning performance of natural sciences (Chemistry, Physics and Biology), in primary education students: elementary and high school, replacing the traditional teaching methodology. Thus, a bibliographic research was conducted dealing with the main teaching techniques involving playful activities. These have promoted an improvement in the students' learning, developing the motivation to study, innovation, sociability and allowing the student to internalize the interrelationships between these disciplines. A bibliographic survey was also conducted considering the contributions of several authors in the databases: Base Nacional Comum Curricular, Google Scholar, Scielo, Youtube, among others, seeking from their arguments to show the benefits of these strategies in the teachinglearning process of the students. The results demonstrate that the use of music, games and plays promote an improvement in student learning and stimulate cognitive skills that favor sociability, motivation and arouse the interest of the student in relation to the content addressed in the classroom. From this review, it was concluded that the use of classroom ludicity in the development of learning is very effective.
\end{abstract}

Keywords: Natural sciences; Recreational activities; Basic education. 


\begin{abstract}
Resumen
El objetivo de ese trabajo es discurrir sobre las principales estrategias de enseñanza que vienen siendo utilizadas actualmente para promover una mejora en el rendimiento de aprendizaje de las ciencias naturales (Química, Física y Biología), en alumnos de la educación básica: enseñanza primaria y secundaria, en sustitución de la metodología tradicional de enseñanza. De esa forma, se realizó una investigación bibliográfica tratando de las principales técnicas de enseñanza envolviendo las actividades lúdicas. Estas, han promovido una mejora en el aprendizaje de los estudiantes, desarrollando la motivación para estudiar, la innovación, la sociabilidad y permitiendo que el estudiante consiga internalizar las interrelaciones entre esas disciplinas. Se realizó también una investigación bibliográfica considerando las contribuciones de varios autores en las bases: Base Nacional Común Curricular, Google Académico, SciELO, Youtube, entre otras, buscando a partir de la argumentación de estas evidenciar los beneficios de esas estrategias en el proceso de enseñanza-aprendizaje de los discentes. Los resultados demuestran que la utilización de música, juegos y piezas teatrales promueven una mejora en el aprendizaje estudiantil y estimulan habilidades cognitivas que favorecen la sociabilidad, la motivación y despiertan el interés del alumno con relación al contenido abordado en el aula. A partir de esa revisión, se concluyó que es bastante efectiva la utilización de la ludicidad en el aula en el desarrollo del aprendizaje.
\end{abstract}

Palabras clave: Ciencias naturales; Actividades lúdicas; Educación básica.

\title{
1. Introdução
}

Esse artigo tem como finalidade discorrer sobre as principais estratégias de ensino que recentemente se utilizam da ferramenta da ludicidade para auxiliar no processo de aprendizagem de alunos da educação básica (ensino fundamental e médio), sobretudo nas disciplinas de Ciências Naturais (Biologia, Física e Química). Dessa forma, o presente trabalho se fundamenta nas seguintes questões apresentadas abaixo: Será que os métodos tradicionais de ensino de ciências naturais que se limitam basicamente à memorização de fórmulas, conceitos e cálculos são suficientes para garantir um aprendizado eficiente por parte do corpo discente? A metodologia de ensino baseada em atividades lúdicas poderá ser utilizada pelo professor a fim de proporcionar elementos que favoreçam o sucesso do ensino-aprendizagem?

Cabe salientar que a Base Nacional Comum Curricular (Brasil, 2018), ao mencionar as competências específicas para o ensino de ciências da natureza nos anos finais do ensino fundamental, consideram como imprescindíveis as ações de estímulo ao letramento científico, pois estas são capazes de proporcionar ao discente a compreensão e interpretação do mundo (em seus aspectos natural, social e tecnológico) bem como transformá-lo baseando-se nos aportes teóricos e processuais contidos nas Ciências. A Lei de Diretrizes e Bases da Educação Nacional (Brasil, 1996), ao tratar das atividades desenvolvidas no âmbito do ensino de Ciências recomenda que estas desenvolvam a curiosidade; o respeito e o estímulo à pluralidade de ideias e opiniões; à persistência na busca de soluções e a compreensão do conhecimento adquirido a partir de atividades de cunho teórico e experimental; a valorização da vida e a preservação do meio ambiente; o apreço e a aceitação à individualidade e a coletividade.

Neste sentido, para alcançar os objetivos propostos acima, se torna essencial que o professor procure tornar suas aulas mais dinâmicas e envolventes, de forma que o aluno a perceba como um momento em que ele está assimilando e vivendo algo novo, não dissociado de sua realidade (Gomes \& Merquior, 2017). Dessa maneira, torna-se indispensável o emprego de tarefas que fujam do tradicional esquema das aulas teóricas, dentre estas atividades podem ser empregadas àquelas que possuem caráter lúdico. Vale mencionar que etimologicamente, o termo lúdico deriva do latim ludus e está associado às brincadeiras, jogos de regras, recreação, teatro e as competições; ou qualquer outra atividade que possui a finalidade de gerar prazer quando de sua execução, ou seja, divertir o praticante (Oliveira, 2017).

Todos os indivíduos podem se beneficiar da prática da ludicidade, tanto pela perspectiva da diversão e do prazer, quanto pela perspectiva da aprendizagem. Por meio das atividades lúdicas explora-se e reflete-se sobre a realidade e a cultura na qual vivemos e incorporamos e, ao mesmo tempo, questionam-se as regras e os papéis sociais (Gonzaga et al., 2017). Diante do exposto, o objetivo principal deste trabalho é investigar se a utilização da ludicidade no ensino de ciências por parte do professor contribui efetivamente para melhora na aprendizagem dos discentes em relação às tradicionais e citar algumas 
propostas de atividades de fácil acesso que possam ser utilizadas no âmbito escolar. É relevante citar ainda que esse artigo foi fundamentado nas ideias e concepções das seguintes obras a seguir: Barros et al. (2013); Base Nacional Comum Curricular (Brasil, 2018); Belo et al. (2019); Bezerra et al. (2018); Brasil (1996); Coelho et al. (2020); Gerhard e Rocha Filho (2012); Gonzaga et al. (2017); Pedrancini et al. (2007); Silva Junior e Barbosa (2009), entre outros.

\section{Metodologia}

A pesquisa é do tipo exploratória e descritiva com uma abordagem qualitativa (Ludke \& André, 2013). Para atingir os objetivos propostos nesse trabalho, utilizou-se como procedimento metodológico a revisão bibliográfica por meio das bases de dados do Google Acadêmico, SciELO, Youtube, dentre outras; realizada a partir da análise e avaliação minuciosa de materiais das duas últimas décadas publicados sobre a temática, a saber: artigos científicos divulgados por meio impresso e eletrônico; revistas científicas; documentos expedidos por órgãos governamentais, anais de trabalhos apresentados em eventos acadêmicos, entre outros.

\section{Resultados e Discussão}

Hoje, a aprendizagem das ciências naturais no ensino fundamental e médio é dificultada, muitas vezes, devido à ausência de interdisciplinaridade entre as disciplinas de química, física e biologia que compõem o currículo escolar. Além disso, a falta de interação dos próprios assuntos ministrados em sala de aula não contribui para o efetivo processo de ensinoaprendizagem. Essa integração de conteúdos depende de vários fatores tais como: a essência da própria disciplina, as características e afinidades dos alunos, a formação do professor e até mesmo das condições físicas onde ocorre o processo de ensino-aprendizagem (Gerhard \& Rocha Filho, 2012). Dessa forma, nota-se que a educação promovida no ambiente escolar não tem permitido que os alunos se apropriem dos conhecimentos científicos de modo a internalizá-los, questioná-los e utilizálos como ferramenta de raciocínio que extrapole situações de ensino e aprendizagem eminentemente escolares. Boa parte do conhecimento científico transmitido na escola cai rapidamente no esquecimento, prevalecendo ideias empíricas ligadas ao senso comum; bastante consolidadas e resistentes, podendo ser identificadas até mesmo entre estudantes universitários (Coelho et al., 2020).

Além disto, ocorre a fragmentação dos assuntos, sem uma interligação bem definida, assim como, a falta de interesse de certas instituições de ensino, ligadas ao governo ou não, que interferem, direta ou indiretamente, na maneira com que as formas de ensino são organizadas, dificultando a elaboração de estratégias para sintetizar e dar coerência ao conjunto de saberes do currículo escolar, sendo dessa forma, quase impossível à visualização dos processos de forma integrada e interdisciplinar. Diante do exposto, é possível observar que o modo com que o ensino está estruturado, organizado e conduzido atualmente é pouco eficaz em promover o desenvolvimento conceitual (Pedrancini et al., 2007).

Nesse sentido, várias pesquisas relacionadas ao ensino de Ciências Naturais foram realizadas para comprovar os pontos de vista supracitados, como se verifica no trabalho de Silva Junior e Barbosa (2009). Os autores afirmam que muitos estudantes do ensino médio manifestam dificuldades para compreender conceitos relacionados ao pensamento biológico ministrados em diferentes níveis de complexidade durante o ensino fundamental e médio. Segundo os pesquisadores, os discentes procuram manter pensamentos sincréticos em relação aos conteúdos básicos estudados, não conseguindo estabelecer uma ideia definida sobre estrutura celular, confundindo este conceito com o de tecido, átomo ou molécula. Em grande parte, isso é devido à ausência de interdisciplinaridade entre os conteúdos e a falta de diálogo entre diferentes disciplinas da mesma área do conhecimento.

Os estudos de Santos et al. (2013) demonstram que mais de 50\% dos estudantes do ensino médio apresentam dificuldades em relação à aprendizagem de Química devido a base matemática deficitária. Os autores afirmam que a 
matemática ensinada de forma essencialmente algébrica e centrada no uso de fórmulas, cálculos e memorizações excessivas são alguns dos principais fatores que contribuem para o desestímulo, e surgimento de dificuldades na aprendizagem dos estudantes. Belo et al. (2019) afirmam que a metodologia empregada pelo professor, na hora de transmitir os conteúdos, tem impacto direto sobre a aprendizagem dos discentes, principalmente, se parte do conteúdo a ser ministrado já tiver sido abordado em outras etapas da educação básica.

Barroso et al. (2018) ao investigarem as dificuldades de aprendizagem dos estudantes de Física no Exame Nacional do Ensino Médio - ENEM, perceberam que os alunos concluintes desta etapa final da educação básica, não conseguiram assimilar os conteúdos de mecânica, fenômenos térmicos e ótica geométrica por escolherem os distratores relacionados a ideias presentes em sua estrutura cognitiva que não possuem caráter científico. Os autores ressaltam que, apesar do crescimento das pesquisas na área de Física realizadas a partir da década de 80, o impacto destas pesquisas nos processos de ensinoaprendizagem foi mínimo, e que somente uma pequena parte deste conhecimento foi incorporada aos livros didáticos e cursos de formação de professores, demonstrando a eventual predominância destas concepções empíricas no cotidiano escolar. Nesse contexto, a utilização do lúdico pode ser uma forma de despertar o interesse do aluno pelas Ciências Naturais, podendo esse transformar o meio em que está inserido pela internalização efetiva desse conhecimento e sua aplicação em prol da sociedade, comprometido com os princípios de solidariedade (Barbosa \& Jófili, 2004).

Entre as atividades lúdicas que poderão ser utilizadas pelos professores, estão à música, os jogos, as peças de teatro, entre outras. A música, seja inventada ou na forma de paródias criadas pelos alunos, podem propiciar um interesse e uma motivação pelos conteúdos de Ciências de maneira a facilitar a sua compreensão e assimilação. Conforme Cruz et al. (2020), essa forma de ludicidade bastante executada nas metodologias de práticas do ensino infantil é um importante recurso didático também para o ensino de Química, Física e Biologia; e pode ser uma opção divertida e atrativa, pois o ensino do conteúdo escolar através de paródias musicais podem transformar conteúdos tediosos e de difícil assimilação em atividades interessantes e atraentes.

Dessa forma, pode-se inferir que a música é uma maneira eficaz de promover a interação entre as pessoas, desempenhando um papel muito importante na vida destas. Ela é marcante e constante e mesmo não fazendo parte do currículo da educação básica de forma mais efetiva, pode ser muito bem aproveitada no ambiente escolar. A música ainda contribui para o desenvolvimento cognitivo, envolve o aluno com a matéria estudada, além de promover a sua socialização (Barros et al., 2013). No site do Youtube é possível encontrar diversas músicas e paródias criadas por professores e alunos ligadas aos conteúdos de Ciências Naturais que poderão ser utilizadas em sala de aula, conforme o Quadro 1, seguinte:

Quadro 1: Paródias encontradas no Youtube relativas aos conteúdos de Química, Física e Biologia.

\begin{tabular}{|c|c|c|c|}
\hline DISCIPLINA & $\begin{array}{c}\text { TÍTULO DA } \\
\text { PARÓDIA/COMPONENTE } \\
\text { CURRICULAR }\end{array}$ & DESCRIÇÃO DO VÍDEO & LINK DO VÍDEO \\
\hline & $\begin{array}{l}\text { Rap da Pilha - Físico-Química: } \\
\text { Pilhas: Oxidação e Redução }\end{array}$ & $\begin{array}{l}\text { O vídeo retrata o funcionamento de uma } \\
\text { Pilha de Daniell ressaltando os } \\
\text { processos de oxirredução ocorridos no } \\
\text { ânodo e no cátodo e a importância da } \\
\text { ponte salina. }\end{array}$ & $\begin{array}{l}\text { https://www.youtube.com/watch?v=d- } \\
\text { HIBS7jaaQ\&ab_channel=UTI\%7CUnididade } \\
\text { deTratamentoIntelectual }\end{array}$ \\
\hline & $\begin{array}{l}\text { Que Facito! Química Geral: } \\
\text { Ligações Químicas }\end{array}$ & $\begin{array}{l}\text { A mídia ressalta as diferenças } \\
\text { encontradas em ligações iônicas, } \\
\text { covalentes e metálicas por meio das } \\
\text { classificações dos grupos presentes na } \\
\text { Tabela Periódica e da Regra do Octeto. }\end{array}$ & $\begin{array}{l}\text { https://www.youtube.com/watch?v=1ek1Q8f } \\
\text { NTdA\&ab_channel=Prof.Marx- } \\
\text { MundodaQu\%C3\%ADmica }\end{array}$ \\
\hline
\end{tabular}




\begin{tabular}{|c|c|c|c|}
\hline \multirow[t]{3}{*}{ QUÍMICA } & $\begin{array}{l}\text { Identificação das } \quad \text { Funções } \\
\text { Orgânicas. Química } \\
\text { Funções Orgânicas }\end{array}$ & $\begin{array}{l}\text { A música apresenta as características } \\
\text { estruturais dos grupos funcionais } \\
\text { relacionadas as principais funções } \\
\text { orgânicas abordadas no Ensino Médio. }\end{array}$ & $\begin{array}{l}\text { https://www.youtube.com/watch?v=bTIbVVg } \\
\text { T9Fg\&ab_channel=EscoladoSebrae }\end{array}$ \\
\hline & $\begin{array}{l}\text { Aprenda Modelos Atômicos em } 3 \\
\text { minutos. Química Geral: Modelos } \\
\text { Atômicos - Estudo do Átomo }\end{array}$ & $\begin{array}{l}\text { Os autores desta paródia retratam as } \\
\text { principais diferenças entre os Modelos } \\
\text { Atômicos de Dalton - Thomson e } \\
\text { Rutherford. }\end{array}$ & $\begin{array}{l}\text { https://www.youtube.com/watch?v=ijBXrZh5 } \\
\text { B7U\&ab_channel=SamuelMonteiro }\end{array}$ \\
\hline & $\begin{array}{l}\text { Funk do Linus Pauling - Química } \\
\text { Geral: Diagrama de Linus Pauling - } \\
\text { Distribuição Eletrônica }\end{array}$ & $\begin{array}{l}\text { Nesta canção, os alunos aprendem a } \\
\text { construir e utilizar o Diagrama de Linus } \\
\text { Pauling. }\end{array}$ & $\begin{array}{l}\text { https://www.youtube.com/watch?v=va- } \\
\text { MkFRRGwk\&list=RDRFYl- } \\
\text { 9hGBN4\&index=9\&ab_channel=Prof.Marx- } \\
\text { MundodaQu\%C3\%ADmica }\end{array}$ \\
\hline \multirow{5}{*}{ FÍSICA } & $\begin{array}{l}\text { Paródia de Física: Movimentos } \\
\text { (Palpite). Mecânica: cinemática, } \\
\text { movimento e estática. }\end{array}$ & $\begin{array}{l}\text { Neste vídeo são apresentadas as } \\
\text { características do movimento uniforme } \\
\text { e uniformemente variado, ressaltando as } \\
\text { fórmulas aplicadas e a conversão das } \\
\text { unidades. }\end{array}$ & $\begin{array}{l}\text { https://www.youtube.com/watch?v=Uq43A0q } \\
\text { SyVA\&ab_channel=PIBIDF\%C3\%8DSICA }\end{array}$ \\
\hline & $\begin{array}{l}\text { Paródia de Física: Já sei Calcular } \\
\text { (Já sei namorar). Eletricidade: } \\
\text { Circuitos elétricos e cálculo da ddp. }\end{array}$ & $\begin{array}{l}\text { Esta composição é baseada nas Leis de } \\
\text { Ohm enfatizando os cálculos para } \\
\text { diferença de potencial em circuitos } \\
\text { elétricos. }\end{array}$ & $\begin{array}{l}\text { https://www.youtube.com/watch?v=twvR6H } \\
\text { N8Cyk\&list=RDtwvR6HN8Cyk\&start_radio } \\
\text { =1\&ab_channel=PIBIDF\%C3\%8DSICA }\end{array}$ \\
\hline & $\begin{array}{l}\text { Paródia de Física Despacito (É o } \\
\text { Atrito). Leis de Newton. Mecânica: } \\
\text { Atrito }\end{array}$ & $\begin{array}{l}\text { O vídeo retrata sobre os principais } \\
\text { fatores que influenciam na força de } \\
\text { atrito. }\end{array}$ & $\begin{array}{l}\text { https://www.youtube.com/watch?v=7saNjwK } \\
\text { aXdw\&ab_channel=RenielCarvalho }\end{array}$ \\
\hline & $\begin{array}{l}\text { Paródia de Física: Ai Se Eu Te } \\
\text { Pego (Propagação de Calor). } \\
\text { Termodinâmica: Propagação de } \\
\text { Calor }\end{array}$ & $\begin{array}{l}\text { A obra menciona as diferenças entre os } \\
\text { processos de propagação de calor: } \\
\text { condução, convecção e irradiação. }\end{array}$ & $\begin{array}{l}\text { https://www.youtube.com/watch?v=oo4fES1t } \\
\text { nxk\&list=RDtwvR6HN8Cyk\&index=2\&ab_c } \\
\text { hannel=PIBIDF\%C3\%8DSICA }\end{array}$ \\
\hline & $\begin{array}{l}\text { Paródia de Física, ondas mecânicas } \\
\text { e ondas eletromagnéticas. } \\
\text { Ondulatória: Ondas Mecânicas e } \\
\text { Eletromagnéticas. }\end{array}$ & $\begin{array}{l}\text { Nesta mídia é apresentada a definição } \\
\text { de onda e as diferenças entre uma onda } \\
\text { mecânica e uma onda eletromagnética. }\end{array}$ & $\begin{array}{l}\text { https://www.youtube.com/watch?v=M8vOA } \\
\text { Y2U1_I\&ab_channel=VemAprenderF\%C3\% } \\
\text { ADsica }\end{array}$ \\
\hline \multirow{5}{*}{ BIOLOGIA } & $\begin{array}{l}\text { As fases da mitose eu sei de cor. } \\
\text { Citologia: Fases da Mitose }\end{array}$ & $\begin{array}{l}\text { Nesta cantiga se destacam os principais } \\
\text { atributos das quatro fases da mitose: } \\
\text { prófase, metáfase, anáfase e telófase }\end{array}$ & $\begin{array}{l}\text { https://www.youtube.com/watch?v=MY0D5p } \\
\text { zN81w\&list=RDQMe7FAmdlp8yM\&start_ra } \\
\text { dio=1\&ab_channel=BioloHits }\end{array}$ \\
\hline & $\begin{array}{l}\text { Organelas Citoplasmáticas. Música } \\
\text { Citologia: } \quad \text { Organelas } \\
\text { Citoplasmáticas }\end{array}$ & $\begin{array}{l}\text { O vídeo menciona as funções dos } \\
\text { lisossomos, retículo endoplasmático liso } \\
\text { e rugoso, e das mitocôndrias. }\end{array}$ & $\begin{array}{l}\text { https://www.youtube.com/watch?v=2- } \\
\text { 3mcPqOArY\&list=PLJ_GUYv7NqgTmahbV } \\
\text { btQV_UpsuPN828gh\&ab_channel=MeGusta } \\
\text { Bio }\end{array}$ \\
\hline & $\begin{array}{llr}\text { Sistema Circulatório } & \text { Música. } \\
\text { Sistemas do Corpo Humano: } \\
\text { Sistema Circulatório }\end{array}$ & $\begin{array}{l}\text { Esta paródia ressalta a passagem do } \\
\text { sangue pelos órgãos do sistema } \\
\text { circulatório. }\end{array}$ & $\begin{array}{l}\text { https://www.youtube.com/watch?v=3mLpDw } \\
\text { VU- } \\
\text { 40\&list=PLJ_GUYv7NqgTmahbVbtQV_Ups } \\
\text { uPN828gh\&index=2\&ab_channel=MeGusta } \\
\text { Bio }\end{array}$ \\
\hline & $\begin{array}{llr}\text { Vitaminas - Paródia Professor } \\
\text { Gustavo (Me Gusta Bio). } \\
\text { Bioquímica: Vitaminas. }\end{array}$ & $\begin{array}{l}\text { A obra destaca para que servem as } \\
\text { vitaminas: } \mathrm{A}, \mathrm{B} 1, \mathrm{C}, \mathrm{D}, \mathrm{E} \text { e } \mathrm{K} \text {. }\end{array}$ & $\begin{array}{l}\text { https://www.youtube.com/watch?v=4yvh7sr1 } \\
\text { Ifk\&ab_channel=MeGustaBio }\end{array}$ \\
\hline & $\begin{array}{l}\text { Doenças virais - Paródia Professor } \\
\text { Gustavo. Vírus: Doenças Virais }\end{array}$ & $\begin{array}{l}\text { A canção retrata as arboviroses e outras } \\
\text { doenças virais, ressaltando a profilaxia } \\
\text { de cada uma delas e a importância das } \\
\text { vacinas. }\end{array}$ & $\begin{array}{l}\text { https://www.youtube.com/watch?v=NrbpqZQ } \\
\text { 4ToA\&list=PLJ_GUYv7NqgTmahbVbtQV_ } \\
\text { UpsuPN828gh\&index=17\&ab_channel=MeG } \\
\text { ustaBio }\end{array}$ \\
\hline
\end{tabular}


Fonte: Autores.

Outro método que também pode ser utilizado na escola é o jogo, por se tratar de uma atividade que tem função lúdica e que pode ainda exercer a função educativa. Buscar o equilíbrio entre essas funções é relevante, pois, se a ludicidade prevalecer, não passará de um simples jogo e se a função educativa for predominante será apenas mais um material didático (Bortolotto et al., 2015). De acordo com Perovano et al. (2017) os jogos, além de apresentarem os elementos do prazer e do esforço espontâneo, integram várias dimensões do aluno, como o envolvimento afetivo e o trabalho em equipe. Dessa forma, eles devem ser inseridos como impulsores nos trabalhos escolares como se pode observar nos trabalhos descritos no Quadro 2.

Quadro 2: Utilização de jogos como impulsionadores da aprendizagem no âmbito escolar.

\begin{tabular}{|c|c|c|c|c|}
\hline DISCIPLINA & NOME DO JOGO & CONTEÚDO & CONCLUSÃO DO ESTUDO & REFERÊNCIA \\
\hline \multirow[b]{2}{*}{ QUÍMICA } & 'Perfil Químico' & Tabela Periódica & $\begin{array}{l}55 \% \text { dos alunos afirmaram que houve uma maior } \\
\text { aprendizagem do conteúdo através do jogo do que } \\
\text { com as aulas teóricas. }\end{array}$ & $\begin{array}{l}\text { (Romano et al., } \\
\text { 2017) }\end{array}$ \\
\hline & $\begin{array}{l}\text { 'Jogo Virtual de } \\
\text { Química' }\end{array}$ & História da Química & $\begin{array}{l}\text { As atividades lúdicas melhoraram as relações } \\
\text { interpessoais entre alunos e professores e } \\
\text { aumentaram o interesse dos estudantes sobre } \\
\text { assuntos abordados em aula. }\end{array}$ & $\begin{array}{l}\text { (Benedetti Filho et } \\
\text { al., 2019) }\end{array}$ \\
\hline \multirow[b]{2}{*}{ FÍSICA } & $\begin{array}{l}\text { 'Fazendo Compras' } \\
\text { 'O Trânsito' } \\
\text { 'Caça ao Tesouro' } \\
\text { 'Ilha do Tesouro' } \\
\text { 'Dama' }\end{array}$ & $\begin{array}{l}\text { Movimento Retilíneo } \\
\text { Uniforme, } \\
\text { Uniformemente Variado, } \\
\text { e Circular Uniforme } \\
\text { (MRU, MRUV, MCU). }\end{array}$ & $\begin{array}{l}\text { Apesar dos jogos terem sido bem recebidos pelos } \\
\text { alunos, houve algumas dificuldades na } \\
\text { compreensão das regras, pois foi realizada a } \\
\text { adaptação de jogos existentes para utilização em } \\
\text { sala de aula. }\end{array}$ & $\begin{array}{l}\text { (Fontes et al., } \\
2016)\end{array}$ \\
\hline & 'Quiz Online' & Ótica Geométrica & $\begin{array}{l}\text { A maioria dos alunos relatou que a gamificação } \\
\text { aplicada em sala de aula contribuiu para a } \\
\text { aprendizagem da disciplina, por conter desafios } \\
\text { durante as atividades, estimulando assim a } \\
\text { aprendizagem. }\end{array}$ & $\begin{array}{l}\text { (Silva \& Sales, } \\
2017)\end{array}$ \\
\hline \multirow[b]{2}{*}{ BIOLOGIA } & $\begin{array}{l}\text { 'Trilha Fotossintética: } \\
\text { passa ou repassa' }\end{array}$ & Fotossíntese & $\begin{array}{l}\text { O método tradicional aliado a uma estratégia } \\
\text { lúdica, que consistiu na exposição teórica- } \\
\text { explicativa do conteúdo seguida da aplicação do } \\
\text { jogo, proporcionou resultados melhores no } \\
\text { processo de ensino-aprendizagem em relação ao } \\
\text { método puramente tradicional ou lúdico. }\end{array}$ & $\begin{array}{l}\text { (Pereira et al., } \\
2020)\end{array}$ \\
\hline & 'Bingo da Célula' & Biologia Celular & $\begin{array}{l}\text { Com a aplicação do jogo observou-se um clima de } \\
\text { diversão e brincadeira que favoreceu os alunos na } \\
\text { aquisição do conhecimento de Biologia Celular. }\end{array}$ & $\begin{array}{l}\text { (Gonçalves et al., } \\
\text { 2014) }\end{array}$ \\
\hline
\end{tabular}

Fonte: Autores.

Os jogos são indicados como um tipo de recurso didático educativo que podem ser utilizados em momentos distintos, como na exposição de um assunto, demonstração e ilustração de informações relevantes do conteúdo ministrado, como revisão da matéria ou síntese de conceitos importantes e avaliação dos assuntos já desenvolvidos (Bortolotto et al., 2015). Miranda (2001) afirma que quando o professor utiliza essa estratégia em sala de aula, muitos benefícios pedagógicos intimamente ligados à aprendizagem são desenvolvidos como a: percepção, ligação com o conteúdo ministrado, sociabilização, interesse e criatividade. No quadro a seguir, estão demonstrados alguns estudos com a aplicação de jogos na área de Ciências da Natureza. 
O teatro também é outra ferramenta que o professor pode utilizar para promover uma melhora no aprendizado dos discentes. Em seu trabalho, Barbosa e Jófili (2004) deixa claro que as artes cênicas vêm a ser uma das estratégias mais promissoras no ensino de ciências, pois o principal significado da arte na educação é compreender que ela é formada a partir de modos específicos de manifestação da atividade criativa e capacidade de inventar do homem, ao interagirem com o mundo que o cerca, ao se conhecerem, e ao conhecê-lo.

O estudo de caso realizado por Machado e Matos (2012) utilizou o teatro como estratégia lúdica para a melhoria do processo de ensino-aprendizagem de alunos do $2^{\mathrm{a}}$ ano do Ensino Médio em Nova Iguaçu no estado do Rio de Janeiro. A metodologia utilizada pelos pesquisadores consistiu inicialmente na explicação do conteúdo 'organelas citoplasmáticas' do componente curricular de Biologia utilizando o quadro branco (metodologia tradicional de ensino). Em seguida, foi desenvolvida uma peça chamada "A fábrica celular" com sete alunos pertencentes ao Grêmio escolar. Estes alunos deveriam ser responsáveis pelo roteiro da peça, figurino e direção.

Após o período de ensaios, os alunos apresentaram a peça no horário da aula de Biologia e em seguida foi aplicado um questionário de avaliação (contendo 05 questões relativas ao conteúdo abordado na encenação e 01 de abordagem psicossocial) com os alunos expectadores. A maioria dos alunos conseguiu assimilar os conteúdos encenados (65\%) e na questão psicossocial, os discentes solicitaram por unanimidade, aulas com abordagens lúdicas e divertidas. Para Bezerra et al. (2018), a utilização de metodologias que abordem o teatro científico estimulam a interdisciplinaridade e o desenvolvimento do senso crítico pelo aluno, assim como desenvolvem competências e habilidades cognitivas relacionadas ao trabalho em equipe, ao compromisso, a responsabilidade e a solidariedade. No Quadro 3 pode-se observar que vários grupos de pesquisa têm desenvolvido atividades correlacionando o teatro com o ensino de Ciências da Natureza, buscando a interdisciplinaridade e aliando as habilidades artísticas com os assuntos elencados no currículo escolar.

Quadro 3: Peças teatrais aplicadas ao ensino de Química, Física e Biologia.

\begin{tabular}{|c|c|c|c|}
\hline DISCIPLINA & $\begin{array}{c}\text { NOME DA PEÇA } \\
\text { TEATRAL/GRUPO TEATRAL }\end{array}$ & SINOPSE DA OBRA & REFERÊNCIA \\
\hline \multirow[t]{4}{*}{ QUÍMICA } & $\begin{array}{l}\text { 'A Liga da Ciência' - Encenada pelo } \\
\text { Teatro Científico da Seara da Ciência } \\
\text { da Universidade Federal do Ceará - } \\
\text { UFC. }\end{array}$ & $\begin{array}{l}\text { A peça se inicia com um conflito, através de experiências, } \\
\text { entre o vilão Mercúrio, que almeja usar os seus } \\
\text { conhecimentos para destruir a Seara, a Liga da Ciência e } \\
\text { os Super-heróis Quimicoman, Hidrogênia, Nitrogênia e } \\
\text { Oxigênia. }\end{array}$ & (Ventura et al., 2018) \\
\hline & $\begin{array}{l}\text { 'Heróis da Ciência' - Realizada pelo } \\
\text { grupo teatral "Os loucos também } \\
\text { amam" da Escola Estadual Graciliano } \\
\text { Ramos em parceria com a } \\
\text { Universidade Federal de Alagoas - } \\
\text { UFAL. }\end{array}$ & $\begin{array}{l}\text { A obra apresenta uma liga de "Super Heróis/ Herónas" } \\
\text { que buscam proteger as Ciências, a literatura, os museus e } \\
\text { as comunidades indígenas contra os vilões que querem } \\
\text { destruir o planeta. }\end{array}$ & (Santos \& Melo, 2020) \\
\hline & $\begin{array}{l}\text { 'Carruagem Triunfal do Antimônio' } \\
\text { - Apresentada pelos alunos da Escola } \\
\text { Estadual Orlando Venâncio dos Santos } \\
\text { com a contribuição dos alunos do } \\
\text { PIBID da Universidade Federal de } \\
\text { Campina Grande -UFCG. }\end{array}$ & $\begin{array}{l}\text { O enredo aborda um breve histórico da química, por meio } \\
\text { da Alquimia, onde se destaca o encontro de dois } \\
\text { alquimistas e ações situacionais relacionados à História da } \\
\text { Química. }\end{array}$ & (Sousa et al., 2015) \\
\hline & $\begin{array}{l}\text { 'Meu Céu de Estrelas' - Idealizada } \\
\text { pelos alunos do Curso de Licenciatura } \\
\text { em Física do CEFET de São Paulo. }\end{array}$ & $\begin{array}{l}\text { O principal objetivo desta encenação foi facilitar o ensino } \\
\text { de noções básicas sobre a astronomia, com a apresentação } \\
\text { de temas que possam motivar o aluno. Os principais } \\
\text { assuntos abordados na peça foram as Leis de Kepler. }\end{array}$ & $\begin{array}{l}\text { (Moura \& Teixeira, } \\
\text { 2010) }\end{array}$ \\
\hline
\end{tabular}




\begin{tabular}{|c|c|c|c|}
\hline \multirow{2}{*}{ FÍSICA } & $\begin{array}{l}\text { 'Férias astrais' - A obra foi exibida } \\
\text { pelos discentes do Ensino } \\
\text { Fundamental II da Escola Municipal } \\
\text { Dinarte Mariz, em Mossoró/RN. }\end{array}$ & $\begin{array}{l}\text { Foram evidenciados alguns conceitos sobre o surgimento } \\
\text { do universo e como as civilizações observavam o céu, os } \\
\text { planetas e as constelações. Também foi retratada a } \\
\text { participação dos pensadores ao longo da História da } \\
\text { Ciência, como: Claudio Ptolomeu, Nicolau Copérnico, } \\
\text { Tycho Brahe, Johannes Kepler, Galileo Galilei, Isaac } \\
\text { Newton, entre outros. }\end{array}$ & (Silva et al., 2013) \\
\hline & $\begin{array}{l}\text { 'A História da Astronomia e as } \\
\text { Descobertas de Galileu' - Realizada } \\
\text { por estudantes de uma escola da rede } \\
\text { particular localizada no município de } \\
\text { Jaboatão dos Guararapes-PE }\end{array}$ & $\begin{array}{l}\text { A encenação destacou as teorias ligadas ao Geocentrismo } \\
\text { e Heliocentrismo; assim como as contribuições de Galileu } \\
\text { à Astronomia; as ideias dos estudantes sobre a ciência } \\
\text { como verdade absoluta, ou não; e o entendimento das } \\
\text { Três Leis de Kepler. }\end{array}$ & (Baldow \& Silva, 2014) \\
\hline \multirow[t]{3}{*}{ BIOLOGIA } & $\begin{array}{l}\text { 'Da boca para o coração - Do nariz } \\
\text { para o coração - Do coração para os } \\
\text { neurônios' - Propostas de peças } \\
\text { teatrais que poderão ser aplicadas nas } \\
\text { aulas de Ciências/Biologia. }\end{array}$ & $\begin{array}{l}\text { As três partes da peça demonstram a importância da } \\
\text { alimentação e a interação de diversos órgãos e sistemas } \\
\text { do corpo humano para proporcionar um fim comum à } \\
\text { nutrição das células, em particular das células do sistema } \\
\text { nervoso. }\end{array}$ & (Melo \& Feitoza, 2010) \\
\hline & $\begin{array}{l}\text { 'Teatro de Célula' -Arquitetado por } \\
\text { estudantes do Ensino Médio Integrado } \\
\text { do Curso de Agropecuária do IFRO. }\end{array}$ & $\begin{array}{l}\text { Essa encenação teve por objetivo facilitar o aprendizado e } \\
\text { a compreensão do conteúdo "compartimentos celulares" } \\
\text { de forma lúdica, motivadora e divertida. }\end{array}$ & Menegazzo (2018) \\
\hline & $\begin{array}{l}\text { 'Marina e o coração' - Construída } \\
\text { por alunos do Curso de Ciências } \\
\text { Biológicas da Universidade Federal de } \\
\text { Goiás - UFGO. }\end{array}$ & $\begin{array}{l}\text { Esta obra foi baseada nos conteúdos curriculares } \\
\text { relacionados ao sistema circulatório, respiratório e } \\
\text { nervoso da disciplina de Anatomia Humana. }\end{array}$ & $\begin{array}{l}\text { (Silva; Silva; Souza } \\
\text { 2001) }\end{array}$ \\
\hline
\end{tabular}

Fonte: Autores.

Conforme a Base Nacional Comum Curricular (Brasil, 2018); Machado e Matos (2012) a integração entre as Ciências Naturais e a Arte tem como consequências novas perspectivas de ensino, ou seja, ver a forma de ensinar sob um novo ponto de vista, o que possibilita a interação do ensino de Biologia com suas ações do dia a dia, tais como: cuidados com o corpo, alimentação e sexualidade; e do ensino de Química e Física com assuntos ligados ao cotidiano do aluno; cabendo ao professor a função de nortear o posicionamento do discente frente estas questões estimulando sempre o protagonismo juvenil e o letramento científico.

\section{Conclusão}

Diante do exposto, concluiu-se que a utilização de atividades lúdicas como jogos, músicas e paródias, peças teatrais, entre outras brincadeiras no ensino das Ciências da Natureza (Química, Física e Biologia) tem promovido uma melhora no rendimento dos discentes por facilitarem o desenvolvimento da aprendizagem através da promoção da criatividade, sociabilização, motivação e prazer ao estudar jogando.

Cabe destacar que o professor enquanto, mediador do processo de ensino aprendizagem deve utilizar essas ferramentas e se adequar as demandas desse século no que diz respeito à substituição do processo tradicional de ensino baseado no decorar de fórmulas e equações, conceitos, cálculos, entre outros, sem estar atrelado ao cotidiano discente.

Dessa forma, busca-se a interdisciplinaridade entre essas áreas de modo a aproximar o aluno do conteúdo estudado em sala de aula, permitindo que ele desenvolva o raciocínio crítico-reflexivo de modo a utilizar esses conhecimentos para alterar sua realidade social e modificar o espaço em que está inserido, podendo propor soluções para os diversos problemas sociais, e promover o interesse e o desenvolvimento da ciência no nosso país. 
Sugere-se para trabalhos futuros, a elaboração de estudos de caso em diferentes níveis de ensino da educação básica, que permitam compreender a percepção discente e docente sobre o uso da ludicidade através das metodologias ativas em educação, bem como, analisar a práxis pedagógica com a aplicação de uma ou mais ferramentas educacionais elencadas nesta pesquisa.

\section{Referências}

Baldow, R., \& Silva, A. P. T. B. (2014). Galileu, Kepler e suas descobertas: análise de uma peça teatral vivenciada com estudantes do Ensino Fundamental e Médio. Experiências Em Ensino de Ciências, 9(2), 45-68.

Barbosa, R. M. N., \& Jófili, Z. M. S. (2004). Aprendizagem Cooperativa no Ensino de Química - Parceria que dá certo. Ciência \& Educação, 10(1), 55-61.

Barros, M. D. M. de, Zanella, P. G., \& Araújo-Jorge, T. C. (2013). A música pode ser uma estratégia para o ensino de Ciências Naturais? Analisando concepções de professores da Educação Básica. Revista Ensaio, 15(1), 81-94.

Barroso, M. F., Rubini, G., \& Silva, T. da. (2018). Dificuldades na aprendizagem de Física sob a ótica dos resultados do Enem. Revista Brasileira de Ensino de Física, 40(4), e4402. https://doi.org/http://dx.doi.org/10.1590/1806-9126-RBEF-2018-0059

Belo, T. N., Leite, L. B. P., \& Meotti, P. R. M. (2019). As dificuldades de aprendizagem de química: um estudo feito com alunos da Universidade Federal do Amazonas. Scientia Naturalis, 1(3), 1-9.

Benedetti Filho, E., Santos, C. G. P. dos, Cavagis, A. D. M., \& Benedetti, L. P. dos S. (2019). Desenvolvimento e aplicação de um jogo virtual no ensino de Química. Informática Na Educação: Teoria \& Prática, 22(3), 144-157.

Bezerra, R. da S., Alves, L. A., \& Nunes, A. O. (2018). Uma visão interdisciplinar do ensino de ciências por meio do teatro científico. Abakós, 7(1), 47-67.

Bortolotto, M. M., Gerônimo, V., Lima, M. C., \& Michels, M. L. (2015). Bingo Quimisabe para o estudo da Química no Ensino Médio. Revista Cadernos Acadêmicos, 7(1), 99-107.

Brasil. Ministério da Educação. (2018). Base Nacional Comum Curricular.

Brasil. Ministério da Educação. (1996). LDB: Lei de diretrizes e bases da educação nacional. In Senado Federal. http://portal.mec.gov.br/seesp/arquivos/pdf/lei9394_ldbn1.pdf

Coelho, F. T., Silva, É. D., \& Pirovani, J. C. M. (2020). Percepção de estudantes do ensino médio de uma escola pública do Espírito Santo sobre o ensino de Biologia. Olhares \& Trilhas, 22(3), 381-402. https://doi.org/10.14393/ot2020v22.n.3.57134

Cruz, N. da S. N., Brito, H. E. M., Sousa, F. J. de, \& Cardozo, R. M. D. (2020). A ludicidade no ensino de química: o uso da música como facilitador do processo de ensino-aprendizagem. Brazilian Journal of Development, 6(7), 51179-51186. https://doi.org/10.34117/bjdv6n7-675

Fontes, A. da S., Ramos, F. P., Schwerz, R. C., \& Cargnin, C. (2016). Jogos adaptados para o ensino de Física. Ensino, Saúde e Ambiente, 9(3), 226-248.

Gerhard, A. C., \& Rocha Filho, J. B. da. (2012). A fragmentação dos saberes na educação científica escolar na percepção de professores de uma escola de ensino médio. Investigações Em Ensino de Ciências, 17(1), 125-145.

Gomes, L. O., \& Merquior, D. M. (2017). O uso dos jogos e atividades lúdicas no ensino médio em Química. Revista UNIABEU, 10(24), 187-205.

Gonçalves, R. R., Martello, A. R., Epple, B., Laurence, C., Desbessel, J., \& Post, P. (2014). Bingo da Célula: uma ferramenta metodológica para o ensino de Biologia Celular. Ensino \& Pesquisa, 12(1), 28-47.

Gonzaga, G. R., Miranda, J. C., Ferreira, M. L., Costa, R. C., Freitas, C. C. C., \& Faria, A. C. de O. (2017). Jogos didáticos para o ensino de Ciências. Educação Pública, 17(7), 1-12.

Ludke, M., \& Andre, M. E . D. A. (2013). Pesquisas em educação: uma abordagem qualitativa. E.P.U.

Machado, P. P., \& Matos, W. R. de. (2012). A utilização do Teatro no Ensino de Ciências: um estudo de caso. Revista Rede de Cuidados Em Saúde, 6(1), 111 .

Melo, S. R. de;, \& Feitoza, L. A. (2010). Teatro e Biologia: uma proposta dinâmica para compreender a nutrição dos neurônios e as relações entre os diferentes sistemas envolvidos . Arquivos Do MUDI, 14(1/2/3), 11-18.

Menegazzo, R. F. (2018). Teatro em Biologia contribui para a aprendizagem e pode ser utilizado em outras disciplinas. South American Journal of Basic Education Technical and Technological, 5(2), 113-124.

Miranda, S. de. (2001). No fascínio do jogo, a alegria de aprender. Ciência Hoje, 28(168), 64-64.

Moura, D. de A., \& Teixeira, R. R. P. (2010). O Teatro Científico e o Ensino de Física - Análise de uma experiência didática. Revista Ciência e Tecnologia, 11(18), 1-17.

Oliveira, K. B. de. (2017). Estratégias lúdicas para o ensino de Ciências/Biologia: retratos do V Encontro Nacional de Ensino de Biologia (ENEBIO). Universidade Federal da Fronteira Sul. 
Research, Society and Development, v. 10, n. 6, e16110614643, 2021

(CC BY 4.0) | ISSN 2525-3409 | DOI: http://dx.doi.org/10.33448/rsd-v10i6.14643

Pedrancini, V., Corazza-Nunes, M., Bellanda Galuch, M., Olivo Rosas Moreira, A., \& Claudia Ribeiro, A. (2007). Ensino e aprendizagem de Biologia no ensino médio e a apropriação do saber científico e biotecnológico. Revista Electrónica de Enseñanza de Las Ciencias, 6(2), 299-309.

Pereira, R. J. B., Azevedo, M. M. R., Sousa, E. T. F., \& Hage, A. X. (2020). Método tradicional e estratégias lúdicas no Ensino de Biologia para alunos de escola rural do município de Santarém-PA. Experiências Em Ensino de Ciências, 15(2), 106-123.

Perovano, L. P., Pontara, A. B., \& Mendes, A. N. F. (2017). Dominó inorgânico: uma forma inclusiva e lúdica para Ensino de Química. Conhecimento Online, $9(2), 37-50$.

Romano, C. G., Carvalho, A. L., Mattano, I. D., Chaves, M. R. M., \& Antoniassi, B. (2017). Perfil químico: um jogo para o ensino da Tabela Periódica. Revista Virtual de Quimica, 9(3), 1235-1244. https://doi.org/10.21577/1984-6835.20170072

Santos, A. G. dos; \& Melo, S. C. da S. (2020). O Ensino de Ciências e a peça teatral "Heróis Da Ciência": olhares dos estudantes com deficiência. Revista Educação e (Trans)Formação, Dossiê Tem(dez), 54-71.

Santos, A. O., Silva, R. P., Andrade, D., \& Lima, J. . P. M. (2013). Dificuldades e motivações de aprendizagem em Química de alunos do ensino médio investigadas em ações do (PIBID/UFS/Química). Scientia Plena, 9(7), 1-6. www.scientiaplena.org.br

Silva, J. B. da, \& Sales, G. L. (2017). Gamificação aplicada no ensino de Física: um estudo de caso no ensino de óptica geométrica. Acta Scientiae, 19(5), 782-798.

Silva, F. T. da;, Silva, A. L. S. da, Leyva-Cruz, J. A. ., Miltão, M. S. R. ., \& Andrade-Neto, A. V. (2013). O Teatro como instrumento pedagógico para o Ensino de Física. Caderno de Física Da UEFS, 11(1,2), 43-55.

Silva Junior, A. N., \& Barbosa, J. R. A. (2009). Repensando o ensino de Ciências e de Biologia na Educação Básica : o caminho para a construção do conhecimento científico e biotecnológico. Democratizar, 3(1), 1-15.

Silva, R. A. da;, Silva, M. L. e;, \& Souza, R. (2001). O Ensino de Anatomia através das Artes Cênicas. Arquivos do MUDI, 5(1), 9-14.

Sousa, A. S., Silva, A. dos S., Araújo, D. S. de;, Silva, R. J. D., Costa, E. de O., Lima, R. C. dos S., Oliveira Junior, J. C. de;, Paula, J. C. de F., \& Santos, J. C. O. (2015). O PIBID contextualizando o Ensino de Química através do Teatro. Química: Ciência, Tecnologia e Sociedade, 4(2), 71-80. https://doi.org/10.5151/chenpro-5erq-eq36

Ventura, B., Neves, R. L., Ribeiro, V. G. P., Vale, M. R., Guedes, I., \& Mazzetto, S. E. (2018). Teatro no Ensino de Química: Relato de Experiência. Revista Virtual de Quimica, 10(4), 824-840. https://doi.org/10.21577/1984-6835.20180060 